\title{
DIFFERENTIAL DIAGNOSIS OF PERIARTICULAR FIBROSITIS AND ARTHRITIS*
}

\author{
By C. H. SLOCUMB
}

Periarticular (capsular) fibrositis is much too commonly mistakenly diagnosed as arthritis. At first there may be little or no pain when joints are at rest or in moderate use. Pain or stiffness may be noted only during the first few moments on awakening or after the joints have not been used for a while, or when the joints are used excessively, or when the capsule is stretched. The patient may have to hunt for soreness by twisting his joint sidewise, squeezing it, or flexing it forcefully to convince himself of the actuality of, and of the situation of, pain. After a short experience with these rather intangible symptoms, the patient may note their gradual disappearance.

If the disease progresses pain becomes more constant, chronic aching may appear, and tenderness becomes less elusive. Joints feel stiffer; yet relatively full, though painful, motion may still be readily accomplished. Generally definite swelling or hydrops does not appear. However, capsular thickening may appear. Usually there is little, if any, redness or significant muscular atrophy, and the roentgenograms represent a normal condition. It may be difficult for the patient to limber up on walking. Setting-up exercises, a hot bath, or acetyl-salicylic acid may be required to produce sufficient limberness. Damp or cold weather may make the stiffness or aching worse. Marked fatigue and nervous exhaustion may appear. In spite of these symptoms, physical examination may not disclose anything essentially abnormal. Sometimes gross fibrous nodules are found over the elbows, knuckles, or about the gluteal, sacro-iliac, or occipital regions.

These symptoms may be present for a few days or weeks, for months or years. Vagrancy and variability in the intensity of

* Abstract from a paper read to the American Association for the Study and Control of Rheumatic Diseases; reprinted from the Proceedings of the Staff Meetings of the Mayo Clinic by the courtesy of the author and the publishers. 
symptoms are characteristic, much more so than in atrophic arthritis.

Generally the affection disappears eventually, leaving no deformity of joints. When contractures and deformities do occur, they result from periarticular and not from intra-articular disease.

In the absence of direct pathologic proof, abundant indirect evidence demonstrates the persistent integrity of the joint cavity in cases of fibrositis. In periarticular fibrositis the disease is at the joint, not within the joint. In infectious arthritis, however, there is fibrositis plus synovitis, chondritis, and osteitis.

Clinical Differential Diagnosis ; Comparative Symptomatology. -Periarticular fibrositis and atrophic arthritis have several features in common: incidence by age, manner of onset (acute or chronic), relative incidence by sex, bodily types affected, and prodromal symptoms (fatigue, chilliness, nervous exhaustion). However, certain other features are sufficiently characteristic of each to be helpful in diagnosis.

Joints.-The clinical course of periarticular fibrositis differs from that of atrophic arthritis. In atrophic arthritis there is a tendency to polyarticular invasion. In periarticular fibrositis, although many joints are sometimes affected, often only one or two large joints or several small joints are affected. Articular tenderness is to be expected in cases of atrophic arthritis; in periarticular fibrositis generally little or no tenderness is present.

In atrophic arthritis stiffness of joints is generally objective as well as subjective; in periarticular fibrositis it is frequently only subjective. The symptoms of " jelling ", stiffness of a joint during rest, may be the first or only symptom. Atrophy of muscles is commonly seen in cases of atrophic arthritis but is generally absent in periarticular fibrositis.

In atrophic arthritis three factors produce the appearance of articular swelling: (1) hydrops from the synovial reaction, (2) fibrous thickenings of periarticular tissues, and (3) atrophy of muscle. In periarticular fibrositis there may be slight thickening of periarticular fibrous tissue, but factors 1 and 3 are absent; hence swelling is not notable.

Motion of affected joints usually causes pain to patients who have atrophic arthritis. In periarticular fibrositis there may be no pain on ordinary motion, but pain may be present with unusual, forced, or lateral motion which stretches the capsule. Arthritic 
joints often feel worse after moderate exercise. Joints affected with fibrositis are frequently subjectively better after moderate exercise. They may hurt only the first few minutes of the day and feel all right thereafter. In atrophic arthritis there are few complete remissions or even complete intermission in symptoms; although symptoms vary in intensity there is generally a constant minimum of discomfort. In periarticular fibrositis, complete remissions, particularly short complete intermissions, are frequent. Patients who have periarticular fibrositis experience much more marked variability in intensity and persistence of symptoms than do those who have atrophic arthritis. However, fibrositis may produce symptoms that remain chronic for a long time. In atrophic arthritis there is little or no tendency to migration of symptoms. In periarticular fibrositis different joints are often involved in successive bouts.

Systemic Manifestations.-Atrophic arthritis is a disease of joints attended by many systemic manifestations. Common findings are slight fever, subnormal cutaneous temperature, tachycardia without fever, lowered blood pressure, anorexia, and significant loss of weight. In periarticular fibrositis these are usually absent.

Fatigue and nervous exhaustion are frequent attributes of both diseases, but in atrophic arthritis they are often submerged since the patient does not exert himself much. Patients who have periarticular fibrositis are usually quite active in spite of their pains; hence fatigue and nervous exhaustion are generally marked and are often notable for be.ng out of proportion to the objective evidence of disease.

Weight.-Sixty-two per cent. of patients who had arthritis lost weight; 47 per cent. of them lost more than 10 pounds. Only 7 per cent. of those who had fibrositis lost more than 10 pounds.

Roentgenographic Alterations.-Of one hundred patients who had fibrositis, seventy-eight, who had suffered a total of 284 years of their disease, presented no intra-articular roentgenographic alterations, although thirty-seven patients were forty-five years of age or older. In 22 per cent. of cases there were hypertrophic changes, generally slight, interpreted as evidence of coincident, unrelated, senescent arthritis, since most of the patients were between fifty and sixty-six years of age. Roentgenograms of some patients were negative after ten to twenty-five years of periarticular fibrositis. 
In contrast, in 86 per cent. of cases of atrophic arthritis there was definite roentgenographic alteration. Although half of the hundred patients had had their disease less than a year, only 14 per cent. of the entire group gave negative roentgenograms.

In a given case any intra-articular roentgenographic alteration speaks at once for arthritis (with or without fibrositis). If roentgenograms are negative for six to twelve months, without other definite signs of arthritis, one may favour a diagnosis of periarticular disease. In a case of short duration in which roentgenograms are negative, other data must be relied on for differential diagnosis.

Laboratory Differential Diagnosis.-Regard for clinical differences permits accurate differential diagnosis without recourse to the laboratory, when symptoms have occurred for months or years without objective evidence of intra-articular disease. In the early weeks of a given case, however, differential diagnosis is not easy. Laboratory data may then be helpful. One hundred cases each of fibrositis and atrophic arthritis were studied; cases were selected only to ensure that enough early and late cases of each would be analysed. In the cases of fibrositis the disease had lasted from four weeks to forty years; in arthritis from three weeks to eighteen years.

Sedimentation rate of erythrocytes:-The greatest laboratory differences were observed in estimations of the sedimentation rates of erythrocytes. In cases of fibrositis the average sedimentation rate (at the end of an hour) was $11.6 \mathrm{~mm}$. The rate was normal in 73 per cent., but slightly altered (16 to $25 \mathrm{~mm}$.) in 16 per cent., and significantly altered (25 to $32.5 \mathrm{~mm}$.) in only 11 per cent. The rate was never more than $32.5 \mathrm{~mm}$. Of patients who had rates of more than $20 \mathrm{~mm}$. all but one had had fibrositis more than one year, most of them more than five years.

In contrast the average rate in cases of atrophic arthritis was $71.5 \mathrm{~mm}$. Although 25 per cent. of the arthritic patients had had their disease less than six months, only 3 per cent. had normal rates. Only 6 per cent. had rates between 16 and $25 \mathrm{~mm}$.; 91 per cent. had rates of more than $25 \mathrm{~mm}$. In 67 per cent. of cases the rate was more than $50 \mathrm{~mm}$., and in 23 per cent. it was between 100 and $150 \mathrm{~mm}$.

In atrophic arthritis altered rates were generally noted early, even within the first three to six weeks of the disease. Among 
six patients who had fibrositis of six months' duration or less, only one had an elevated rate $(23.5 \mathrm{~mm}$.).

Blood counts:-Little or no help in differential diagnosis is obtained from total leukocyte counts or erythrocyte counts. Estimation of hæmoglobin gives clearer evidence of anæmia. In the blood of only 5 per cent. of patients who had fibrogitis was the concentration of hæmoglobin less than $13 \mathrm{gm}$., and in that of only one (a patient who had menorrhagia) was the concentration less than $12 \mathrm{gm}$. In 42 per cent. of patients who had arthritis, the concentration of hæmoglobin was less than $13 \mathrm{gm}$. and in 19 per cent. less than $12 \mathrm{gm}$.

Combination of Abnormal Findings. - Elevation of the sedimentation rate and reduction in the erythrocyte count, in concentration of hæmoglobin, or in weight are, of course, not specific for these two diseases. Hence a patient who has periarticular fibrositis might exhibit one of these alterations because of some other cause than his rheumatism. It is well therefore to note that of the hundred cases of fibrositis, in ninety there were either none of these alterations or only one alteration. Those exhibited by the remaining ten patients were practically never sufficiently impressive to be definitely misleading. In contrast the majority of the patients who had atrophic arthritis exhibited two or more alterations that were not slightly but definitely abnormal.

In a given case, therefore, if there is only one slight abnormality in the laboratory findings, too much significance must not be attached thereto. It may be the basis of a guarded, tentative diagnosis of arthritis rather than of a final one of fibrositis. When in doubt, however, I favour making the tentative diagnosis of fibrositis rather than making a more pessimistic appraisal of the condition and running the risk of making a diagnosis of "arthritis" in a case in which it probably does not exist.

\section{Summary ANd Conclusions.}

In any given case, then, the differential diagnosis between periarticular fibrositis and atrophic arthritis is based on a survey of certain direct and certain indirect evidence for or against the presence of intra-articular disease. Direct evidence in favour of intra-articular disease is afforded by the appearance of synovial hydrops and of roentgenographic evidence of disease. Less direct evidence is afforded by the appearance of the joints; 
notable redness, tenderness, muscular atrophy, and definite swelling speak in favour of arthritis, as opposed to disease that is exclusively extra-articular. Indirect evidence is afforded by a history characteristic of one or the other type and by certain laboratory data, particularly the sedimentation rates of erythrocytes and the estimation of hæmoglobin. The weight curve also is significant. Alterations in these data, particularly in two or more factors, if the magnitude of the alterations is beyond a certain maximum generally seen in cases of fibrositis, speak against uncomplicated fibrositis and in favour of articular disease.

The differential diagnosis in favour of periarticular flbrositis is made on the persistence with which direct and indirect evidence of intra-articular disease remains absent. When objective changes, systemic manifestations, and alterations in laboratory findings known to be relatively consistent in cases of atrophic arthritis remain persistently absent, the arthralgia, stiffness, and articular thickening can be with no little confidence ascribed to periarticular fibrositis and the fear of impending arthritis can be laid aside. 